\title{
TEXTILE-INTEGRATED TRANSMITTING UNIT
}

\section{MIROSLAV CUPAL ", JIŘí DŘÍNOVSKÝ ${ }^{+}$, TOMÁŠ GÖTTHANS ${ }^{+}$, JAROSLAV LÁČÍK ${ }^{+}$, JAN PRÁŠEK ${ }^{+}$, ZBYNĚK RAIDA ${ }^{+}$, DITA KRÁČALOVÁ ${ }^{\dagger}$, ZDEŇKA $^{\circ}$ LEDROVÁ $^{\dagger}$, JIŘÍ PROCHÁZKA ${ }^{\dagger}$, DAVID KRUTÍLEK ${ }^{\wedge}$, AND ZDENĚK ŘEZNÍČEK}

${ }^{*+}$ SIX Research Center, Brno University of Technology

Technická 10, 61600 Brno, Czech Republic

e-mail: cupalm@phd.feec.vutbr.cz, web page: www.six.feec.vutbr.cz/

$\dagger$ SINTEX a.s.

Moravská 1078, 56002 Česká Třebová, Czech Republic

e-mail: prochazka@sintex.cz,web page: www.sintex.cz/

Evektor spol. s r.o.

Letecká 1008, 68604 Kunovice, Czech Republic

e-mail: zreznicek@evektor.cz,web page:www.evektor.cz

Key words: Textile-integrated antenna, screen printing, 3D knitted fabric

\begin{abstract}
This contribution deals with the main parts of the textile-integrated transmitting unit, a transmitter and an antenna, operating in the ISM $5.8 \mathrm{GHz}$ band. The transmitter is based on commercially available WLAN UART Serial Port OWS451 and it is controlled via the UART interface by microprocessor ATmega328. The antenna is based on the circular ring-slot concept and it is able to provide monopolar radiation pattern to ensure maximum coverage of the unit. The unit will be integrated in a seat cover and it will transmit the telemetry of sensors integrated in the seat (temperature, pressure...).
\end{abstract}

\section{INTRODUCTION}

In order to reduce weight of small airplanes and consequently decrease their fuel consumption, there is strong motivation to develop and use multifunctional structures. E.g. if textile materials are used, they can fulfill different functions. Apart from their conventional roles of seat or upholstery covers, they can be considered for thermal insulation or mechanical attenuation. In addition, textile materials are nowadays very popular for development of electronic components where they usually play the role of a substrate [1], [2].

In our previous work [2], the attention was focused on the integration of wireless sensor network components into 3 dimensional (3D) knitted fabrics (produced by SINTEX) exploited on a board of a small airplane EV-55 (developed by EVEKTOR) with particular attention on optimized 3D knitted fabric and textile-integrated receiver. In this paper, we will describe the main parts of the textile-integrated transmitting unit, a transmitter and an antenna, operating in the ISM $5.8 \mathrm{GHz}$ band. 


\section{TRANSMITTER}

The transmitter is based on IEEE 802.11a standard that can communicate over the $5 \mathrm{GHz}$ frequency band [3]. The WLAN UART Serial Port OWS451 module has UART interface and fully embedded TCP/IP stack and driver. For real-time data acquisition, due to the dimensions and the selected frequency band, it seems to be the best choice. The module itself is controlled via the UART interface by microprocessor ATmega328. The microprocessor is as well connected through $\mathrm{A} / \mathrm{D}$ converters to a sensor matrix for mechanical pressure sensing. The pressure sensors are piezoresistive fabrics that are made by coating regular fabrics in an inherently conductive polymer. In order to provide data to user, the wireless module is then connected to an AP (Access Point) router or ad-hoc network. Sensor data is sent to a user application that communicates using UDP (User Datagram Protocol). A Python visualization program is created on the user side.
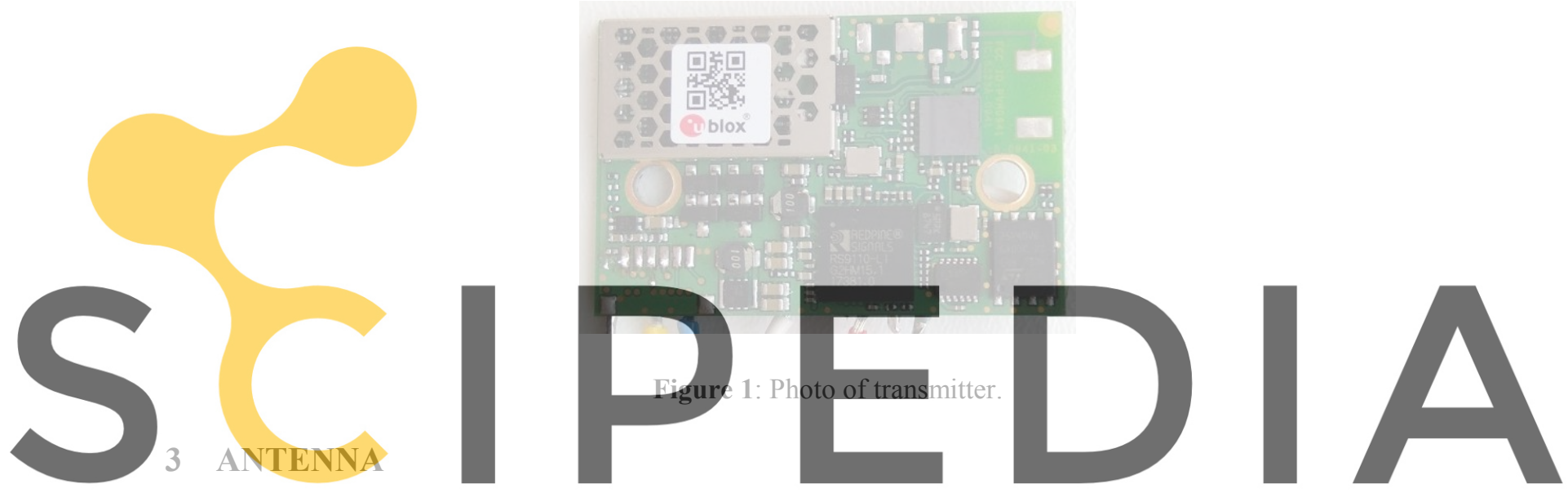

To ensure maximum coverage of the unit, a ring slot antenna [4] was used and integrated

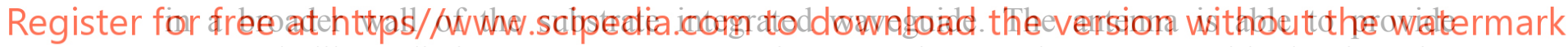
monopole-like radiation pattern. However, in comparison to the antenna with shorting vias [5], the designed antenna is free of vias since the monopole-like radiation pattern is generated by the excitation of higher order mode in the slot. On the other hand, it is larger than it could be if the shorting vias were used.

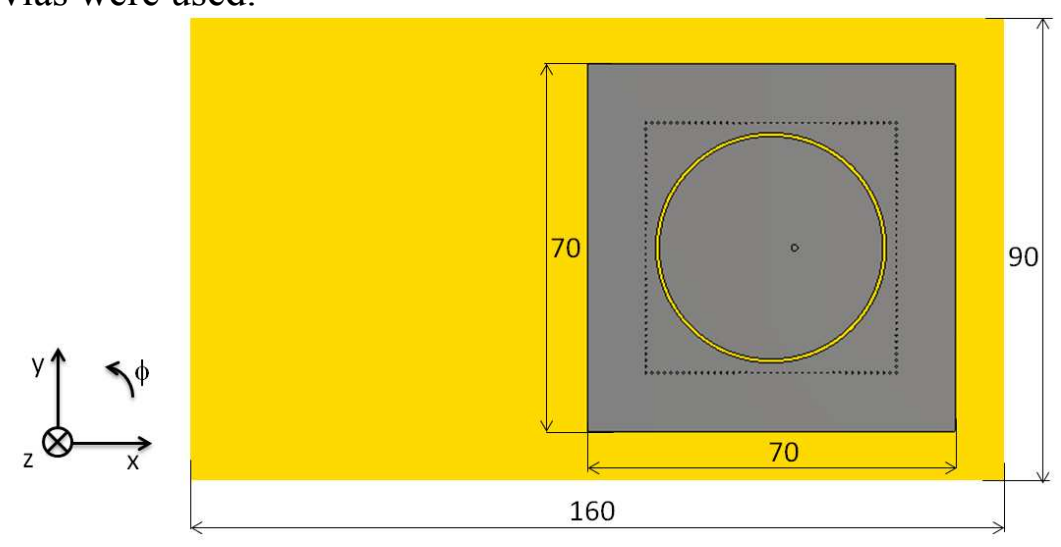

Figure 2: Top view of antenna realized on 3D knitted fabric. 
The geometric configuration of the substrate integrated waveguide (SIW) circular ring-slot antenna is depicted in Figure 2. The antenna is designed on 3D knitted fabric of the thickness $3.4 \mathrm{~mm}$ and the relative permittivity 1.2. The fabric is from both sides covered by Digiflex Master foil from the company Alphaset. The foil was ironed on the fabric. The radiator was screen printed on the top side of the fabric covered be the foil using Aurel mod. C880 semiautomatic screen printer. For the printing, the ESL 1901-S polymer silver conductor paste with good electrical conductivity was used. The same procedure was applied on the bottom side of the fabric covered by the foil to create continues conductive surface of the same size and position, but without the circular slot. To create the vertical walls of the SIW cavity, conductive thread ELITEX ${ }^{\circledR}$ Art, SC 110/f34_PA/Ag was used. To experimentally verify the properties of the antenna, it is equipped by SMA connector. In the final phase, the SMA connector will be replaced by UFL one and the antenna will be connected by a coaxial cable with the transmitter. The fabricated sample of the antenna is depicted in Figure 3.

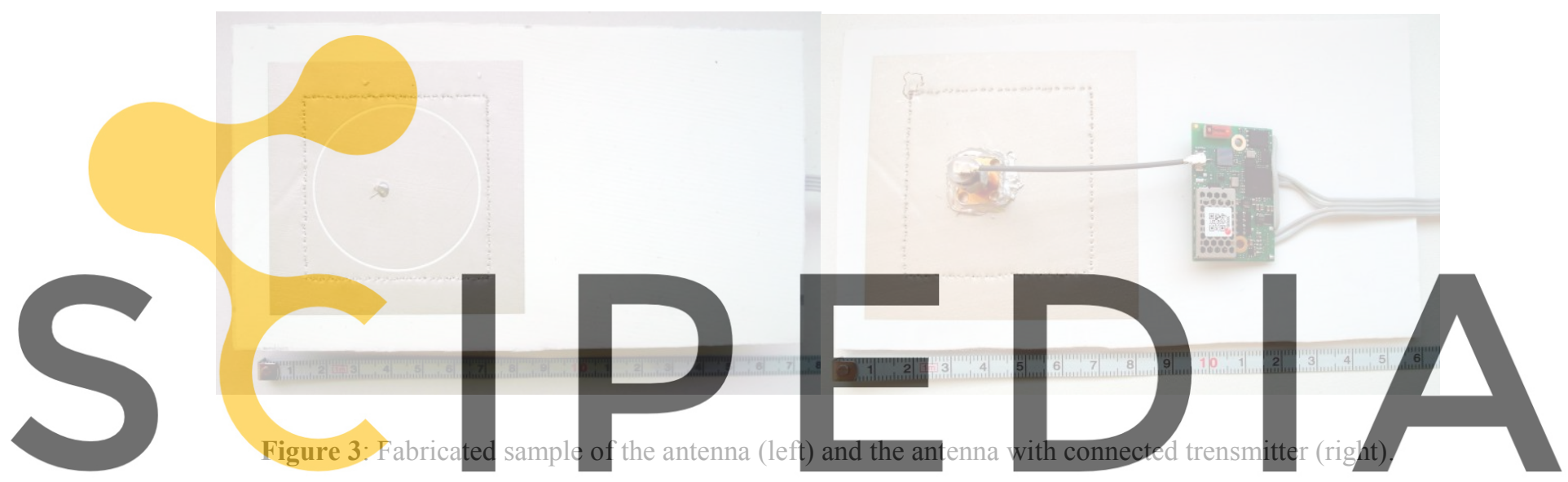

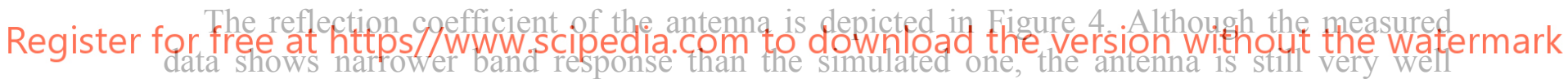
matched in the desired ISM $5.8 \mathrm{GHz}$ band $(5.725-5.875 \mathrm{GHz})$. The difference of simulated and measured response is probably caused due to manufacturing tolerances.

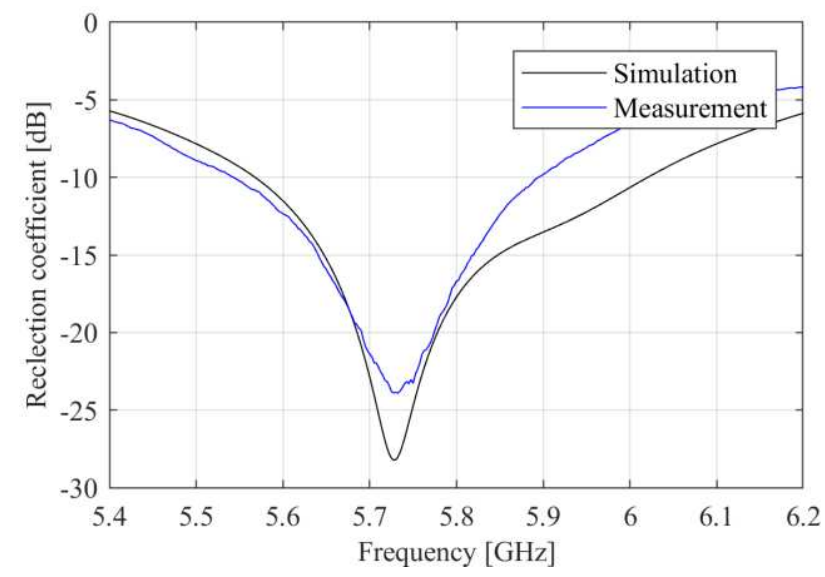

Figure 4: Reflection coefficient of simulated and measured antenna. 
The simulated and measured radiation gain patterns are depicted in Figure 5. We can observe that the antenna is able to provide monopole like radiation pattern. The agreement of simulated and measured results is satisfactory. The measured peak gain of the antenna is about $5 \mathrm{dBi}$.
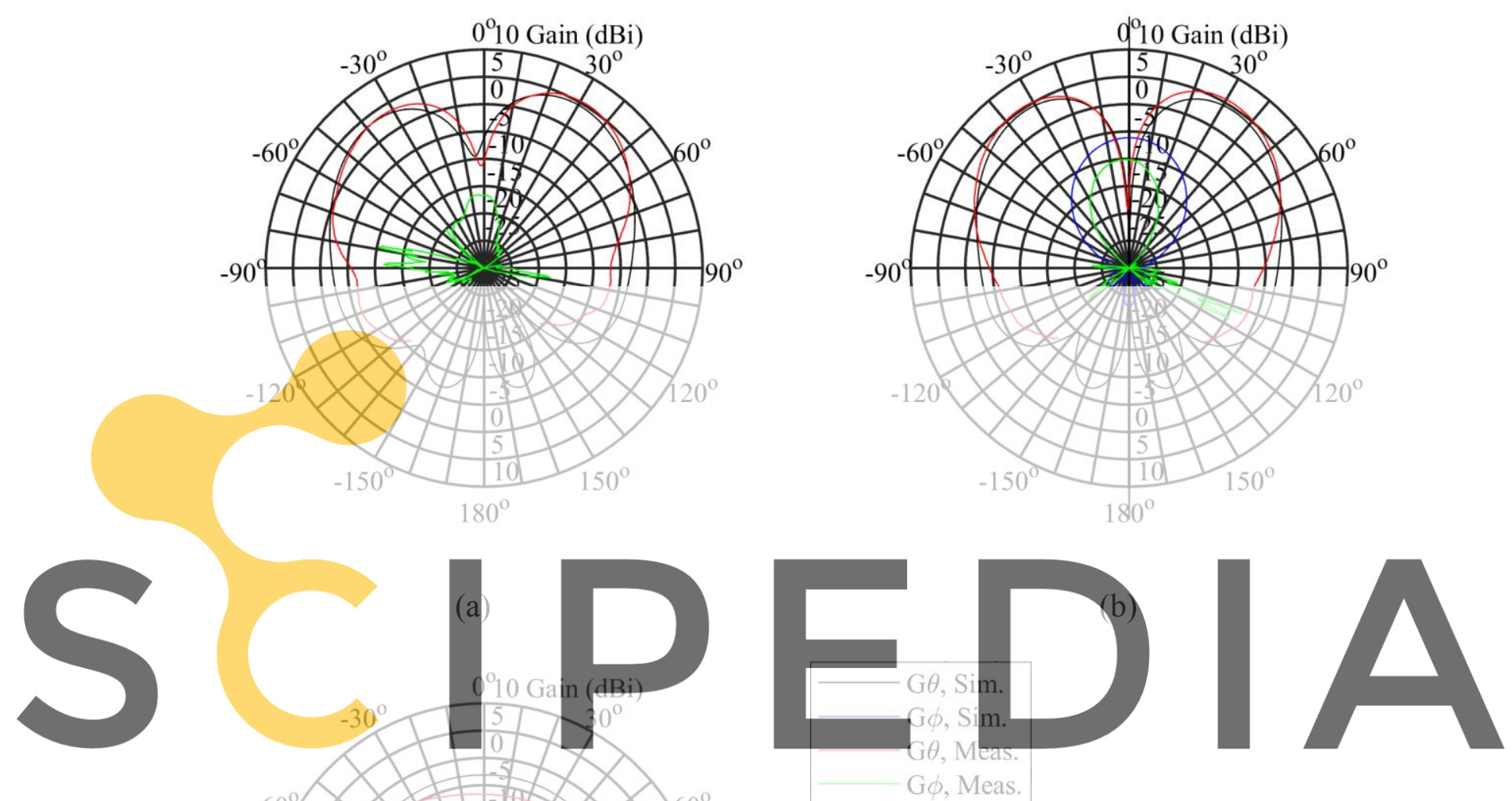

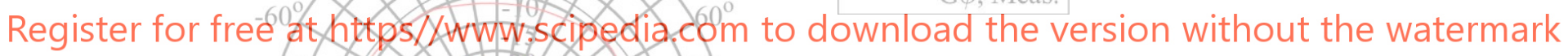

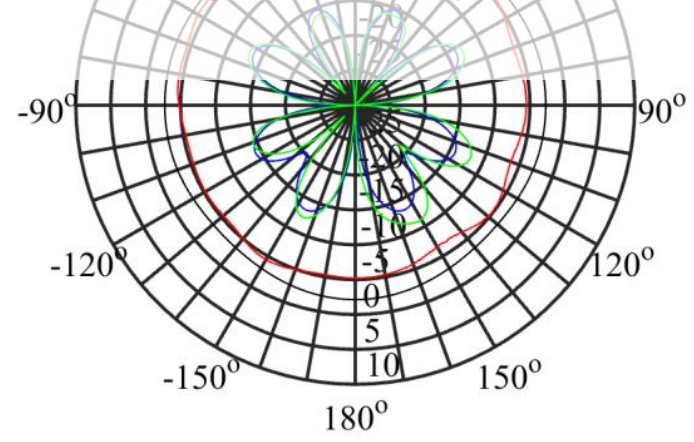

(c)

Figure 5: Radiation gain pattern of antenna at freqeuncy of $5.8 \mathrm{GHz}$ in xz-plane (a), yz-plane (b), and xyplane(c). 


\section{CONCLUSIONS}

In this contribution, the main parts of the textile-integrated transmitting unit, the transmitter and the antenna, operating in the ISM 5.8 GHz band has been described. Now both those parts are being integrated. The final data of the unit will be presented at the conference.

\section{ACKNOWLEDGEMENT}

The described development has been supported by the Czech Ministry of Industry and Trade by the grant FV10087 Intelligent upholstery of vehicles.

\section{REFERENCES}

[1] A. Kiourti, Textile-Based Flexible Electronics for Wearable Applications: From Antennas to Batteries, 2018 2nd URSI Atlantic Radio Science Meeting (AT-RASC), Meloneras, 2018, pp. 1-4.

[2] M. Cupal et al., Textile-integrated electronics for small airplanes, 12th European Conference on Antennas and Propagation (EuCAP 2018), London, 2018, pp. 1-5.

[3] https://www.u-blox.com/sites/default/files/OWL253_ProductSummary_(UBX-14006701).pdf

[4] A. A. Serra, A. R. Guraliuc, P. Nepa, G. Manara, I. Khan and P. S. Hall, Dual-polarisation and dual-pattern planar antenna for diversity in bodycentric communications. IET Microwave, Antennas and Propagation, 2010, vol. 4, no. 1, pp. 106-112.

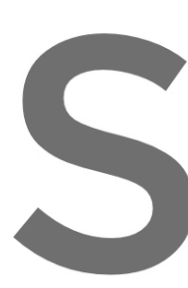

[5] J. Lacik et al., Su
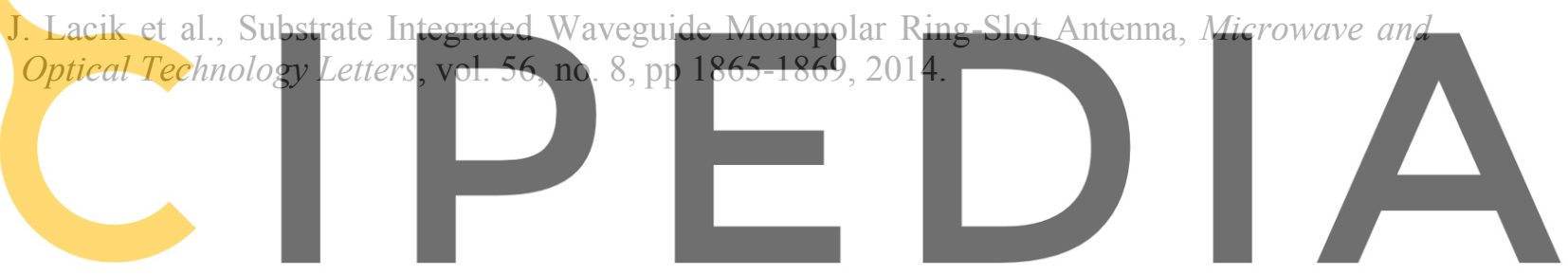

Register for free at https//www.scipedia.com to download the version without the watermark 